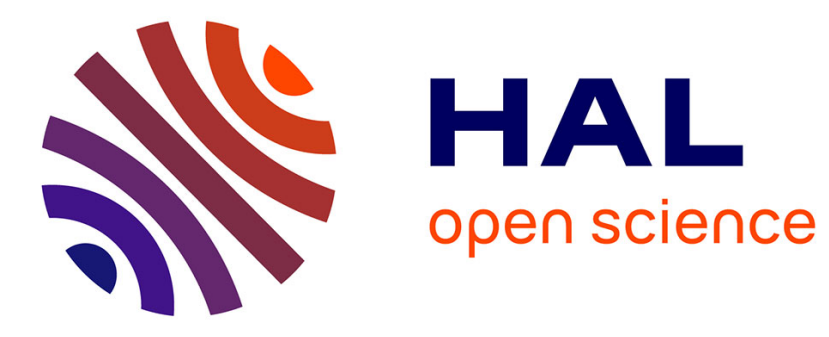

\title{
Stabilization of a new nanocomposite family by reduction of gold nanoclusters with electron-reservoir complexes
}

Fangyu Fu, Anthony Dedieu, Wenjuan Wang, Tao Chen, Yongbo Song, Eric Fouquet, Jean-René Hamon, Manzhou Zhu, Didier Astruc

\section{To cite this version:}

Fangyu Fu, Anthony Dedieu, Wenjuan Wang, Tao Chen, Yongbo Song, et al.. Stabilization of a new nanocomposite family by reduction of gold nanoclusters with electron-reservoir complexes. Chemical Communications, 2019, 55 (69), pp.10277-10280. 10.1039/c9cc05260g · hal-02303388

\section{HAL Id: hal-02303388 https://hal-univ-rennes1.archives-ouvertes.fr/hal-02303388}

Submitted on 2 Dec 2019

HAL is a multi-disciplinary open access archive for the deposit and dissemination of scientific research documents, whether they are published or not. The documents may come from teaching and research institutions in France or abroad, or from public or private research centers.
L'archive ouverte pluridisciplinaire HAL, est destinée au dépôt et à la diffusion de documents scientifiques de niveau recherche, publiés ou non, émanant des établissements d'enseignement et de recherche français ou étrangers, des laboratoires publics ou privés. 


\title{
Stabilization of a New Nanocomposite Family by Reduction of Gold Nanoclusters with Electron-reservoir Complexes
}

\author{
Fangyu Fu, ${ }^{a, b}$ Anthony Dedieu, ${ }^{b}$ Wenjuan Wang, ${ }^{b, c}$ Tao Chen, ${ }^{a}$ Yongbo Song, ${ }^{a}$ Eric Fouquet, ${ }^{b}$ \\ Jean-René Hamon, ${ }^{c}$ Manzhou Zhu, ${ }^{* a}$ and Didier Astruc*b
}

Four stable 19-electron Fe and Co sandwich electronreservoir and three hydride reservoir complexes reduce the prototypal nanocluster $\mathrm{Au}_{25}(\mathrm{SR})_{18}\left(\mathrm{R}=\mathrm{CH}_{2} \mathrm{CH}_{2} \mathrm{Ph}\right)$ leading to a largely increased kinetic stabilization of the anionic nanocluster form compared to previously known nanocluster anion salts; these salts represent new and robust nanocomposite anionic gold clusters with 18-electron sandwich complexes as counter cations.

Precisely defined thiolate-protected gold nanoclusters have recently attracted significant research interest because of their unique catalytic, optical, and electronic properties. ${ }^{1}$ In this category, the spherical nanocluster $\mathrm{Au}_{25}(\mathrm{SR})_{18}\left\{\mathrm{R}=\left(\mathrm{CH}_{2}\right)_{2} \mathrm{Ph}\right\}$, $1{ }^{2}$ has been the most extensively studied. ${ }^{1}$ It is viewed as a typical "superatom", and its neutral and anionic forms have been shown by X-ray crystal structures to contain similar cores $^{2}$ and are reversibly interconverted. ${ }^{3}$ Liu et al reported electron transfer between $\left[\mathrm{Au}_{25}(\mathrm{SR})_{18}\right]^{-} \mathrm{TOA}^{+}\left\{\mathrm{TOA}^{+}=\mathrm{N}(n-\right.$ $\left.\left.\mathrm{C}_{8} \mathrm{H}_{17}\right)_{4}{ }^{+}\right\}$and $\mathrm{TEMPO}^{+} \mathrm{BF}_{4}^{-}, \quad \mathrm{TEMPO}^{+} \mathrm{BF}_{4}^{-}=2,2,6,6-$ tetramethylpiperidin-1-oxoammonium tetrafluoroborate ${ }^{4 a}$ and Chong et al showed that $\left[\mathrm{Au}_{25}(\mathrm{SR})_{18}\right]^{-} \mathrm{TOA}^{+}$served as electron-transfer chain catalyst ${ }^{5}$ for cascade reaction of 2nitrobenzonitrile under ambient conditions. ${ }^{6}$ Although the nanocluster $\left[\mathrm{Au}_{25}(\mathrm{SR})_{18}\right]^{-} \mathrm{TOA}^{+}$is stable in the solid state, however, it suffers from some kinetic instability in solution, and therefore it is only stable for a few hours in $\mathrm{CH}_{2} \mathrm{Cl}_{2}$ solution under ambient conditions. ${ }^{3 b}$ Thus, new syntheses of stable salts of $\left[\mathrm{Au}_{25}(\mathrm{SR})_{18}\right]^{-}$in both solid state and solution are needed in order to provide access to new mixed nanocomposites and

Department of Chemistry and Center for Atomic Engineering of Advancec Materials, Anhui Province Key Laboratory of Chemistry for Inorganic/Organic Hybrid Functionalized Materials, Anhui University, Hefei, Anhui 230601, China.

b. ISM, UMR CNRS N 5255, Univ. Bordeaux, 33405 Talence Cedex, France..

c. Institut des Sciences Chimiques, UMR CNRS 6226, Université de Rennes 1, 35042 Rennes Cedex, France.

*Corresponding author: E-mail: zmz@ahu.edu.cn; didier.astruc@u-bordeaux.fr Electronic Supplementary Information (ESI) available: [General data, details for the synthesis and characterizations of the gold cluster-sandwich complex nanocomposites]. See DOI: 10.1039/x0xx00000x understand the structure-property relationship at the atomic level. Therefore we have envisaged using electron-reservoir and hydride reservoir $\mathrm{Fe}$ and $\mathrm{Co}$ sandwich complexes as reducing agents of the neutral nanocluster 1 forming complex salts of the nanocluster anion $\mathbf{1}$.

The principle of electron-reservoir complexes is that both the reduced and oxidized forms are robust and isostructural, thus readily interconverted, and that the reduced form is very electron-rich, being only oxidized at very negative redox potentials. ${ }^{7}$ The 19-electron complexes $\left[\mathrm{Fe}\left(\eta^{5}-C_{5} R_{5}\right)\left(\eta^{6}\right.\right.$-arene $\left.)\right]$ 8 and $\mathrm{Co}\left(\eta^{5}-\mathrm{C}_{5} \mathrm{R}_{5}\right)_{2}{ }^{9} \quad\{\mathrm{R}=\mathrm{H}$ or $\mathrm{Me})$ belong to this family; in particular the ring ligand permethylation (i.e. $\mathrm{R}=\mathrm{Me}$, arene $=$ $\mathrm{C}_{6} \mathrm{Me}_{6}$ ) strengthens the bulk, robustness and reducing power of these complexes. ${ }^{10}$ The bulk of such electron-reservoir sandwich complexes not only stabilizes small nanoparticles, but also contributes to their excellent catalytic activity. ${ }^{11}$ Here we are using the 19-electron complexes cobaltocene $\left(\mathrm{Cp}_{2} \mathrm{Co}\right)$, 2, $\left[\mathrm{FeCp}\left(\eta^{6}-\mathrm{C}_{6} \mathrm{Me}_{6}\right)\right], \mathbf{3},\left(\mathrm{Cp}=\eta^{5}-\mathrm{C}_{5} \mathrm{H}_{5}\right)$, decamethyl cobaltocene, $\mathrm{CoCp}_{2},\left(\mathrm{Cp}^{*}=\eta^{5}-\mathrm{C}_{5} \mathrm{Me}_{5}\right), 4$ and $\left[\mathrm{FeCp} *\left(\eta^{6}-\mathrm{C}_{6} \mathrm{Me}_{6}\right)\right], 5$ to stoichiometrically reduce the neutral nanocluster 1 to [1; "metallocenium" ${ }^{+}$\& (Scheme 1). The formal potentials of $\left[\mathrm{Au}_{25}(\mathrm{SR})_{18}\right]^{0 /-1}$ is $-0.39 \mathrm{~V}$ vs. ferrocene ${ }^{+/ 0,4}$ and $+0.11 \mathrm{~V}$ vs. decamethylferrocene, $\mathrm{FeCp}_{2}{ }_{2}{ }^{12}$ so that $\mathbf{1}$ is exergonically reduced to $1^{-}$by these four strong organometallic reductants. The exergonicity of these reactions (Figure 1 ) insures fast single-electron transfer. ${ }^{13}$

The driving force of the electron transfer is almost exclusively governed by the respective standard redox potentials $E^{\circ}$ of the donors and acceptor (Figure 1), ${ }^{13}$ because the electrostatic factor in the Rehm-Weller equation is very weak due to the low charges involved and rather large sizes of the electron-

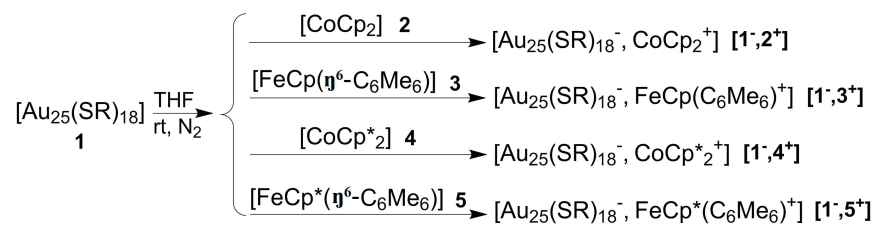

Scheme 1. Synthesis of the salts $\left[\mathrm{Au}_{25}(\mathrm{SR})_{18}{ }^{-}\right.$, metallocenium $\left.{ }^{+}\right]$. 


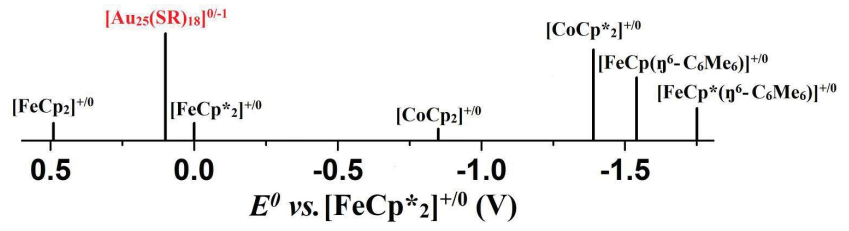

Figure 1. Standard redox potentials of $\mathrm{Fe}$ and Co sandwich complexes vs. $\left[\mathrm{FeCp}_{2}\right]^{+/ 0}$.

transfer substrates. ${ }^{14}$ The 19-electron complexes have oxidation potentials far more negative than the reduction potential of $\mathbf{1}$, therefore they all reduce 1 in a fast reaction. On the other hand, decamethylferrocene, $\mathrm{FeCp}_{2}{ }_{2}, \mathbf{6}$, whose redox potential is almost the same as that of $\mathbf{1}$, does not reduce $\mathbf{1}$ at room temperature for kinetic reasons in a situation of too weak driving force. The fast reaction between 1 and 1 equiv of organometallic sandwich complex 2-5 under $\mathrm{N}_{2}$ at $\mathrm{rt}$ leads to instantaneous color change from yellow brown to red brown at the equivalence point of the reaction (Figure S1).

UV-vis. absorption spectroscopy, which is a convincing physical technique to distinguish salts of diamagnetic $\mathbf{1}^{-}$from paramagnetic $\mathbf{1},^{3 \mathrm{~b}}$ was used before and after reduction of $\mathbf{1}$ (Figure S4). The shoulder at $630 \mathrm{~nm}$ in the spectrum of 1 disappears, while the characteristic absorption band of $\mathbf{1}^{-}$ emerges at $800 \mathrm{~nm}$. Simultaneously, the intensities of the $400-$ $\mathrm{nm}$ band decreases and that of the $450-\mathrm{nm}$ band increases during these electron-transfer reactions.

${ }^{1} \mathrm{H}$ NMR was also used to characterize these four new compounds. The ${ }^{1} \mathrm{H}$ NMR spectra of the diamagnetic $\mathrm{TOA}^{+}$salt was first reproduced in $\mathrm{CD}_{2} \mathrm{Cl}_{2} .{ }^{3 a}$ The ${ }^{1} \mathrm{H}$ NMR spectra of the four diamagnetic salts [1-,"metallocenium" $\left.{ }^{+}\right]$present sharp peaks and are similar to that of $\left[1^{-}, \mathrm{TOA}^{+}\right]$, except for the obvious differences for the cations (Figure S5). This contrasts with the ${ }^{1} \mathrm{H}$ NMR spectrum of 1 that presents broad bands due to the paramagnetism resulting from its electronic structure with an unpaired electron in the HOMO. ${ }^{3}$

The matrix assisted laser desorption ionization mass spectra (MALDI-MS) and electrospray ionization mass spectra (ESI-MS) confirm the formula of the salts $\left[\mathbf{1}^{-}, \mathbf{2}^{+}\right],\left[\mathbf{1}^{-}, \mathbf{3}^{+}\right],\left[\mathbf{1}^{-}, \mathbf{4}^{+}\right]$and $\left[\mathbf{1}^{-}\right.$, $5^{+}$. The left part of Figure 2 and Figure 56 reveal prominent peaks at $\mathrm{m} / \mathrm{z}=7392.44,7391.91,7391.91$ and $7392.03 \mathrm{Da}$ that are assigned to the anion $\mathbf{1}^{-}$(cal. $7392.93 \mathrm{Da}$ ) of the salt [1', metallocenium $^{+}$] (the other peaks are assigned to its fragments). On the right part of Figure 2, a peak at $\mathrm{m} / \mathrm{z}=$ 354.19 Da is observed in positive mode of ESI-MS, showing the cation $\mathbf{5}^{+}$(cal. $\mathbf{3 5 4 . 1 9} \mathrm{Da}$ ) in $\left[\mathbf{1}^{-}, \mathbf{5}^{+}\right]$. In the same way, peaks at

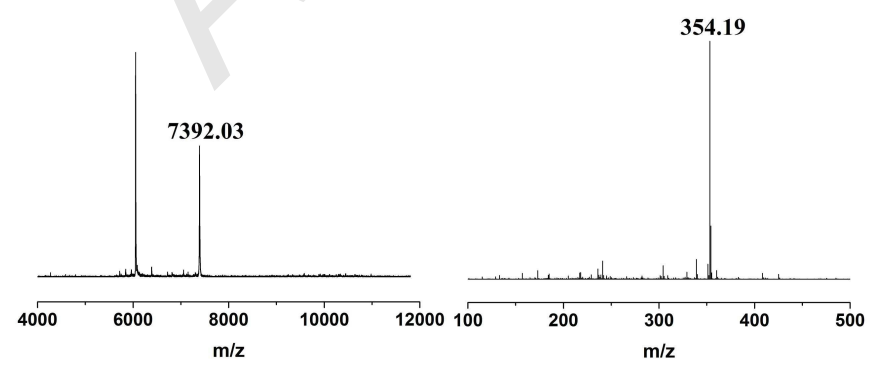

Figure 2. MALDI-MS (left) and ESI-MS (right) analysis of the [1; $\left.5^{+}\right]$.

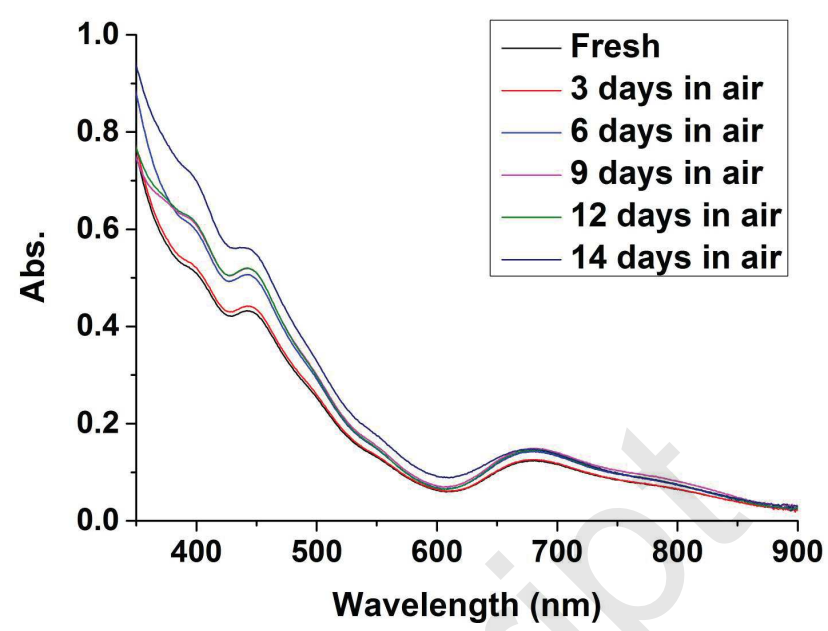

Figure 3. UV-vis. spectra of the nanocluster composite $\left[\mathbf{1}^{-}, \mathbf{5}^{+}\right]$ exposed to air at $r t$ in THF solution.

189.07, 283.20 and 329.27 Da are present in Figure S6a, S6b and S6c, related to $\mathbf{2}^{+}$(cal. $\left.189.01 \mathrm{Da}\right), \mathbf{3}^{+}$(cal. $\left.283.11 \mathrm{Da}\right), \mathbf{4}^{+}$ (cal. $329.17 \mathrm{Da}$ ) in $\left[\mathbf{1}^{-}, \mathbf{2}^{+}\right],\left[\mathbf{1}^{-}, \mathbf{3}^{+}\right]$and $\left[\mathbf{1}^{-}, \mathbf{4}^{+}\right]$, respectively.

UV-vis. absorption spectroscopy allowed studying the counter cation effect on the stability to air of these nanocluster anion salts in THF solution under ambient conditions. The parent cobalticinium salt $\left[\mathbf{1}^{-}, \mathbf{2}^{+}\right]$was stable in air in THF for 2 days, and the iron sandwich salt $\left[\mathbf{1}^{-}, \mathbf{3}^{+}\right]$, that possess 6 methyl groups on the benzene ring, exhibited the same aerobic stability (Figure 57 ). This 2-day stabilization is a great progress compared to the salt $\left[1^{-}, \mathrm{TOA}^{+}\right]$that is stable only for a few hours at rt. However, when methyl groups are present on both ligand rings, i.e. in the cations $4^{+}$of $\left[\mathbf{1}^{-}, \mathbf{4}^{+}\right]$(Figure S8) and $\mathbf{5}^{+}$ of $\left[1^{-}, 5^{+}\right]$(Figure 3 ), these salts both resisted to aerobic oxidation by $\mathrm{O}_{2}$ from air for 14 days at $\mathrm{rt}$ in THF solution.

The similarity between the aerobic stability periods in solution of $\left[1^{-}, 2^{+}\right]$and $\left[1^{-}, 3^{+}\right]$that have in common a $\mathrm{Cp}$ ligand, and a large size difference of the other ligand ( $\mathrm{Cp}$ in $\mathbf{2}$ and $\mathrm{C}_{6} \mathrm{Me}_{6}$ in 3) is remarkable. The permethylation of only one ring in $\mathbf{3}^{+}$in which the six methyl groups introduce a large additional bulk on one side of the sandwich does not bring about any aerobic stability advantage compared to cobalticinium, $\mathbf{2}^{+}$. In addition the dichotomy between the aerobic stability times of the two sub-families ( 2 days for $\left[\mathbf{1}^{-}, \mathbf{2}^{+}\right]$and $\left[\mathbf{1}^{-}, \mathbf{3}^{+}\right]$vs. 14 days for $\left[\mathbf{1}^{-}, \mathbf{4}^{+}\right]$ and $\left[\mathbf{1}^{-}, \mathbf{5}^{+}\right]$) shows a key point for strong aerobic stability increase. These features indicate that the smaller $\mathrm{Cp}$ ligand is facing the $\mathrm{Au}_{25}$ cluster anion in the two former salts (Figures $4 \mathrm{a}$ vs. 4b), whereas both ring permethylations force one of the two permethylated $\mathrm{Cp}^{*}$ ligands to face the Au cluster in the two latter complexes (Figure 4c). This trend takes into account the large aerobic stability increase to 14 days for these two latter salts. It is the bulk of both sandwich ligands that protects the anionic $\mathrm{Au}_{25}{ }^{-}$core. On the other hand the bulk of only one sandwich ligand does not play a decisive role in the Au cluster protection, because it does not directly face the Au cluster anion.

This nanocluster composites $\left[\mathbf{1}^{-}, \mathbf{4}^{+}\right]$and $\left[\mathbf{1}^{-}, \mathbf{5}^{+}\right]$are also stable in air for more than half a year in the solid state under ambient 

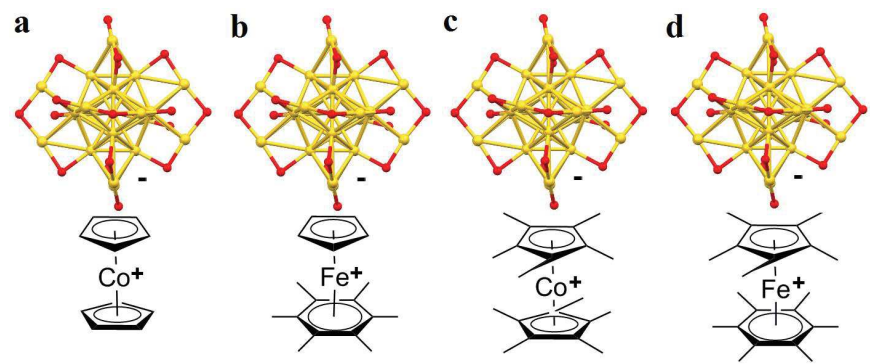

Figure 4. Proposed stabilization mode of the anion $1^{-}$in the salts $a,\left[1^{-}, 2^{+}\right], b,\left[1^{-}, 3^{+}\right], c,\left[1^{-}, 4^{+}\right]$and $d,\left[1^{-}, 5^{+}\right]$.

conditions, which surpasses the stability of $\left[1^{-}, \mathrm{TOA}^{+}\right]$. By comparison, $\left[\mathbf{1}^{-}, \mathrm{Na}^{+}\right]$, synthesized by $\mathrm{NaBH}_{4}$ reduction of $\mathbf{1}$, is oxidized by air within a few minutes to $\mathbf{1}$ in THF solution (Figure S9).

Finally we have also examined the electron-transfer properties to 1 of the 18-electron complexes $\left[\mathrm{CoCp}\left(\eta^{4}-\mathrm{C}_{5} \mathrm{H}_{6}\right), 7,\left[\mathrm{FeCp}\left(\eta^{5}-\right.\right.\right.$ $\left.\mathrm{C}_{6} \mathrm{Me}_{6} \mathrm{H}\right), 8$ and $\left[\mathrm{CoCp} *\left(\eta^{4}-\mathrm{C}_{5} \mathrm{Me}_{5} \mathrm{H}\right), 9\right.$ (Figure 5) that are hydride reservoirs, i.e. good reductants and reversibly interconverted by hydride transfer from the cations $\mathbf{2}^{+}, \mathbf{3}^{+}$and $4^{+}$respectively. ${ }^{15}$ For instance reaction of $2^{+} \mathrm{PF}_{6}^{-}$with $\mathrm{NaBH}_{4}$ is known to yield 7 via a single-electron transfer pathway via $2,{ }^{16}$ but electron-transfer reactions of $\mathbf{7}$ yielding a salt of $\mathbf{2}^{+}$are not known. The complexes 7, 8 and $\mathbf{9}$ indeed rapidly react with $\mathbf{1}$ to form exactly the same nanocomposite salts $\left[\mathbf{1}^{-}, \mathbf{2}^{+}\right],\left[\mathbf{1}^{-}, \mathbf{3}^{+}\right]$ and $\left[1^{-}, \mathbf{4}^{+}\right]$, respectively, as those obtained by reactions of 2,3 and $\mathbf{4}$ with $\mathbf{1}$, as shown by UV-vis. and ${ }^{1} \mathrm{H}$ NMR spectroscopies and mass spectrometry (Figure S10 and S11).

The hydride reservoir complexes 7, 8 and $\mathbf{9}$ have oxidation potentials (resp. $-0.35 \mathrm{~V}, 0.04 \mathrm{~V}$ and $-0.89 \mathrm{~V}$ vs. $\mathrm{Cp}^{*}{ }_{2} \mathrm{Fe}^{+/ 0}$ ) that are less cathodic than those of the related 19-electron complexes 2, 3, and 4, respectively, but about the same or more cathodic than the standard reduction potential of $\mathbf{1}$ (Figure 1). Their reactions with $\mathbf{1}$ are also driven by the irreversibility of the redox reactions, which adds to the
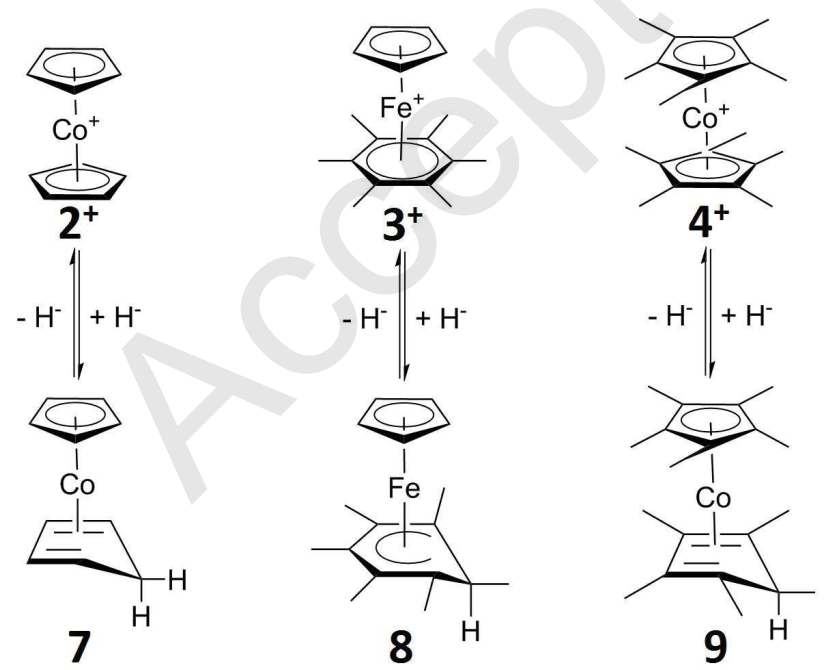

Figure 5. Three stable hydride-reservoir sandwich complexes. Their syntheses involve reactions of the organometallic cations with $\mathrm{NaBH}_{4}$. Hydride abstraction from the neutral complexes yielding the cations is usually conducted with a $\mathrm{Ph}_{3} \mathrm{C}^{+}$salt. ${ }^{15}$ exergonicity to provoke fast electron transfer to 1 . For instance, $\mathbf{8}^{15 \mathrm{c}}$ has the same redox potential as decamethylferrocene that does not react with 1 . The mechanism of these latter reactions is either single electron transfer to $\mathbf{1}$ followed by hydrogen atom loss or direct hydride transfer to 1 followed by hydrogen atom loss. The preserved identity of the gold cluster ligand shell disclosed by mass spectrometry discards hydride substitution of a thiolate ligand, favoring the former hypothesis. The advantages of the use of 7 , $\mathbf{8}$ and $\mathbf{9}$ over $\mathbf{2}, \mathbf{3}$, and $\mathbf{4}$ is that their synthesis is somewhat easier by reaction of the salts of the cations 2,3 and 4 with $\mathrm{NaBH}_{4}$, and $\mathbf{7}$ and $\mathbf{8}$ benefit from stability in air at $\mathrm{rt}$.

In conclusion a new method of synthesis of nanocluster anions has been developed involving a strategy that uses the reduced form of electron-reservoir and hydride reservoir complexes. In this situation, the hydride reservoir complexes behave as electron-transfer reagents as the electron-reservoir complexes. Their hydride transfer properties will be illustrated later in other processes. The flexibility of this method includes the choice of the metal and the ligand bulk of the reducing agent, allowing comparison of the aerobic stabilities provided depending on the geometrical electron-reservoir parameters. The aerobic stability studies conducted by UV-vis. spectroscopy show that the best protection against the kinetic instability in air is brought about by $4^{+}$or $\mathbf{5}^{+}$involving the largest bulk protection by permethylated $\mathrm{Cp}^{*}$ rings near the nanocluster surface. This strategy illustrates some of the applications of the concepts of electron reservoir and hydride reservoir complexes. It could be generalized to the synthesis and stabilization of most cluster anions that present reversibly interconverted redox states, affording structure-reactivity relationship studies towards catalysis, optics and molecular electronic applications.

\section{Conflicts of interest}

The authors declare no competing financial interest.

\section{Notes and references}

\& The significance of "metallocenium" is extended here to the monocationic $\mathrm{Fe}$ and $\mathrm{Co}$ sandwich complexes involved in this study.

1 a) R. Jin, Nanoscale, 2010, 2, 343-362; b) H. Hakkinen, Nat. Chem., 2012, 4, 443-455; c) R. Jin, C. J. Zeng, M. Zhou and Y. X. Chen, Chem. Rev., 2016, 116, 10346-10413; d) J. Fang, B. Zhang, Q. F. Yao, Y. Yang, J. P. Xie and N. Yan, Coord. Chem. Rev., 2016, 322, 1-29; e) I. Chakraborty and T. Pradeep, Chem.Rev., 2017, 117, 8208-8271; f) Q. Yao, T. Chen and X. Yuan, Acc. Chem. Res., 2018, 51, 1338-1348; g) A. W. Cook and T. W. Hayton, Acc. Chem. Res., 2018, 51, 2456 - 2464; h) S. Sharma, K. K. Chakrahari, J.-Y. Saillard and C. W. Liu, Acc. Chem. Res., 2018, 51, 2475-2483; i) T. Higaki, Q. Li, M. Zhou, S. Zhao, Y. Li, S. Li and R. Jin, Acc. Chem. Res., 2018, 51, 2764-2773; j) M. Zhou, T. 
Higaki, G. Hu, M. Y. Sfeir, Y. Chen, D.-e. Jiang and R. Jin, Science, 2019, 364, 279-282; k) Y. Du, H. Sheng, D. Astruc and M. Zhu, Chem. Rev., DOI: 10.1021/acs.chemrev.8b00726.

2 a) M. W. Heaven, A. Dass, P. S. White, K. M. Holt and R. W. Murray, J. Am. Chem. Soc., 2008, 130, 3754-3755; b) M. Zhu, C. M. Aikens, F. J. Hollander, G. C. Schatz and R. Jin, J. Am. Chem. Soc., 2008, 130, 5883-5885.

3 a) J. F. Parker, J.-P. Choi, W. Wang and R. W. Murray, J. Phys. Chem. C, 2008, 112, 13976-13981; b) M. Zhu, M. W. T. Eckenhoff, T. Pintauer and R. Jin, J. Phys. Chem. C, 2008, 112, $14221-14224$; c) Z. Liu, Xu, S. Jin, S. Wang, G. Xu and M. Zhu, Int. J. Hydrogen Energy, 2013, 38, 16722-16726; d) S. Antonello, G. Arrigoni, T. Dainese, M. D. Nardi, G. Parisio, L. Perotti, A. Rene, A. Venzo and F. Maran, ACS Nano, 2014, 8, 2788- 2795.

4 a) Z. Liu, M. Zhu, X. Meng, G. Xu and R. Jin, J. Phys. Chem. Lett., 2011, 2, 2104-2109; b) K. Kwak, Q. Tang, M. Kim, D.-e. Jiang and D. Lee., J. Am. Chem. Soc., 2015, 137, 10833-10840.

5 D. Astruc, Angew. Chem., Int. Ed. Engl., 1988, 100, 662-680.

6 H. Chong, P. Li, S. Wang, F. Fu, J. Xiang, M. Zhou and Y. Li, Sci. Rep., 2013, 3, 3214.

7 a) A. M. Madonik and D. Astruc, J. Am. Chem. Soc., 1984, 106, 2437-2439; b) M.-H. Desbois, D. Astruc, J. Guillin, F. Varret, A. X. Trautwein and G. Villeneuve, J. Am. Chem. Soc., 1989, 111, 5800-5809.

8 a) J.-R. Hamon, D. Astruc and P. Michaud, J. Am. Chem. Soc., 1981, 103, 758-766; b) J. Green, M. R. Kelly, M. P. Payne, A. Seddon, D. Astruc, J.-R. Hamon and P. Michaud, Organometallics, 1983, 2, 211-218; c) D. Astruc, Acc. Chem. Res., 1986, 19, 377-383;

9 a) U. Koelle and F. Khouzoumi, Angew. Chem. Int. Ed., 1980, 19, 640-641; b) B. Gloaguen and D. Astruc, J. Am. Chem. Soc., 1991, 112, 4607-4609.

10 D. Astruc, Electron-transfer and Radical Processes in TransitionMetal Chemistry. VCH, New-York, 1995, Chap. 1.

11. F. Fu, R. Ciganda, Q. Wang, A. Tabey, C. Wang, A. Escobar, A. M . Martinez-Villacorta, R. Hernández, S. Moya, E. Fouquet, J. Ruiz and D. Astruc, ACS Catal., 2018, 8, 8100-8106.

12 a) J. Ruiz and D. Astruc, C. R. Acad. Sci., t. 1, sér. II, 1998, 21-27; b) I. Noviandri, K. N. Brown, D. S. Fleming, P. T. Gulyas, P. A. Lay, A. F. Masters and L. Phillips, J. Phys. Chem. B, 1999, 103, 67136722 ; c) J. Ruiz, M.-C. Daniel and D. Astruc, Can. J. Chem., 2006, 84, 288-299.

13 a) R. Marcus and N. Sutin, Biochem. Biophys. Acta, 1985, 811, 265-322; b) D. Astruc, Electron-Transfer and Radical Processes in Transition Metal Chemistry, Wiley, New York, 1995, Chap. 1.

14. D. Rehm and A. H. Weller, Isr. J. Chem. 1970, 8, 259-271.

15. a) M. L. H. Green, L. Pratt and G. Wilkinson, J. Chem. Soc., 1959, 3753-3767; b) I. U. Khand, P. L. Pauson and W. E. Watts, J. Chem. Soc. C, 1968, 2257-2259; c) F. Fu, R. Ciganda, A. M. MartinezVillacorta, S. Moya, E. Fouquet, J. Ruiz and D. Astruc, Chem. Eur. J. 2018, 24, 6645-6653.

16. P. Michaud, D. Astruc and J. Ammeter, J. Am. Chem. Soc., 1982, 104, 3755-3757.
TOC:

Stability:

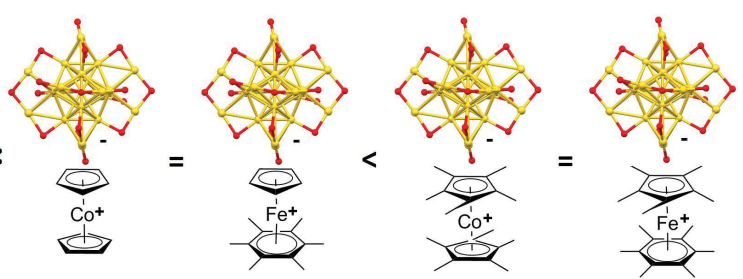

The aerobic stabilities of four new $\mathrm{Au}_{25}$ nanocluster-metal sandwich composites are provided by and related to the metal-sandwich ring sizes. 